Proceedings of Magneto-Optical Recording International Symposium '97, J. Magn. Soc. Jpn., Vol. 22 Supplement No. \$2 (1998), pp. 97-100 (C)1997 by The Magnetics Society of Japan

\title{
THERMAL STABILITY OF AMORPHOUS Tb-Fe ALLOYS ESTIMATED FROM ATOMIC DIFFUSIVITIES
}

\author{
Kazumasa Yamada ${ }^{1}$, Kazuaki Fukamichi ${ }^{2}$ and Yoshiaki Iijima ${ }^{2}$ \\ ' Department of Electrical Engineering, Hakodate National College of Technology, Hakodate 042, Japan \\ 2 Department of Materials Science, Graduate School of Engineering, Tohoku University, Sendai 980-77, Japan
}

Abstract- The activation energies for the structural relaxations in $\mathrm{Tb}_{22} \mathrm{Fe}_{78}$ and $\left(\mathrm{Tb}_{0.22} \mathrm{Fe}_{0.78}\right)_{98} \mathrm{Si}_{2}$ were estimated to be $137-$ $197 \mathrm{kJmol}^{-1}$ and $142-194 \mathrm{kJmol}^{-1}$, respectively. These structural relaxations are attributed to the $\mathrm{Fe}$ atom diffusion. The distribution of the activation energies in $\mathrm{Tb}_{22} \mathrm{Fe}_{78}$ is wider than that in $\left(\mathrm{Tb}_{022} \mathrm{Fe}_{0.78}\right)_{98} \mathrm{Si}_{2}$. The addition of Si improves the thermal stability at low temperatures, corresponding to the temperatures in the pulse-heated areas of magneto-optical recording amorphous media. KEYWORDS: Tb-Fe, AMORPHOUS ALLOY, STRUCTURAL RELAXATION, CURIE TEMPERATURE, COBALT TRACER-DIFFUSION, MAGNETO-OPTICAL DISK

\section{INTRODUCTION}

Thermal stability of amorphous alloys for magnetooptical disks is very important, because the amorphous films are pulse-heated during recording. Structural relaxation processes of amorphous alloys proceed through the atomic diffusion even well below the crystallization temperature. Furthermore, the phase transition from a metastable amorphous state to a stable crystalline state is controlled by diffusion. In the present work, the thermal stability of amorphous $\mathrm{Tb}-\mathrm{Fe}$ and $\mathrm{Tb}-\mathrm{Fe}-\mathrm{Si}$ alloys was studied from the view point of atomic diffusivities of the components.

\section{EXPERIMENTAL PROCEDURES}

Amorphous alloys were made by high-rate de sputtering on a water-cooled $\mathrm{Cu}$ substrate of $1 \mathrm{~mm}$ thickness. To make the amorphous alloys $0.3 \mathrm{~mm}$ thick, the sputtering was carried out for about three days. The amorphous state of the specimens was confirmed by X-ray diffraction with Mo $\mathrm{K} \alpha$ radiation

The structural relaxation and the crystallization processes of amorphous $\left(\mathrm{Tb}_{0.22} \mathrm{Fe}_{0.78}\right)_{100-\mathrm{x}} \mathrm{Si}_{\mathrm{x}}(\mathrm{x}=0,2,4,6,10$ and 20$)$ alloys were examined by DSC measurements after removing the $\mathrm{Cu}$ substrate. Tracer diffusion of ${ }^{57} \mathrm{Co}$ in the amorphous alloys has been studied in the temperature range of $570-633 \mathrm{~K}$ by an ion-beam sputter-microsectioning method.

\section{RESULTS AND DISCUSSION}

The DSC analyses show a broadened exothermic peak before a steep peak due to the crystallization as shown in Figs. $1(\mathrm{a})$-(f), where $\left(\mathrm{Tb}_{0.22 \mathrm{Fe}} .8\right)_{100-x} \mathrm{Si}_{x}(\mathrm{x}=0,2,4,6,10$ and 20$)$ alloys were cyclically heated in the temperature range between $330 \mathrm{~K}$ and $1023 \mathrm{~K}$ at the scan speed of $0.33 \mathrm{Ksec}^{-1}$. The wide exothermic peak observed in the first run decreases remarkably in the second run. The area surrounded by the first and the second heat runs indicates the exothermic heat mainly due to the structural relaxation and crystallization. In Figs. I(a) to (f), the exothermic heat in (a) is much larger than that in (b) to (f). The exothermic heat before the steep peaks in (e) and (f) is much smaller than that in (a) to (d). However, it is difficult to separate the process of the structural relaxation from the crystallization in Fig.1. Therefore, different DSC measurements were made at lower temperatures where no crystallization appears

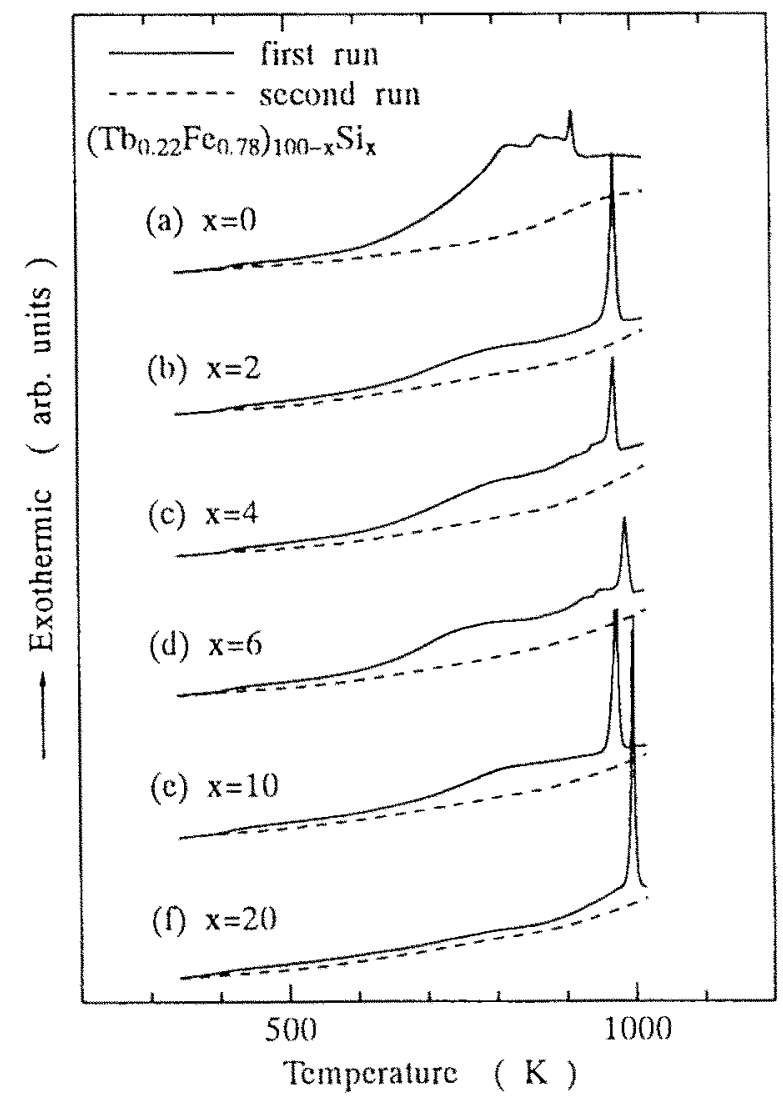

Figure 1 DSC curves of amorphous $\left(\mathrm{Tb}_{0.22} \mathrm{Fe}_{0.78}\right)_{100 \cdot \times \mathrm{Si}}(\mathrm{x}=0$, $2,4,6,10$ and 20) alloys.

Figures 2(a) and (b) show cyclic DSC measurements for 10 times in the temperature range from $330 \mathrm{~K}$ to $650 \mathrm{~K}$ at the scan speed of $0.4 \mathrm{Ksec}^{-1}$. The large exothermic heat observed in the first heat run remarkably decreases in the second heat run. 


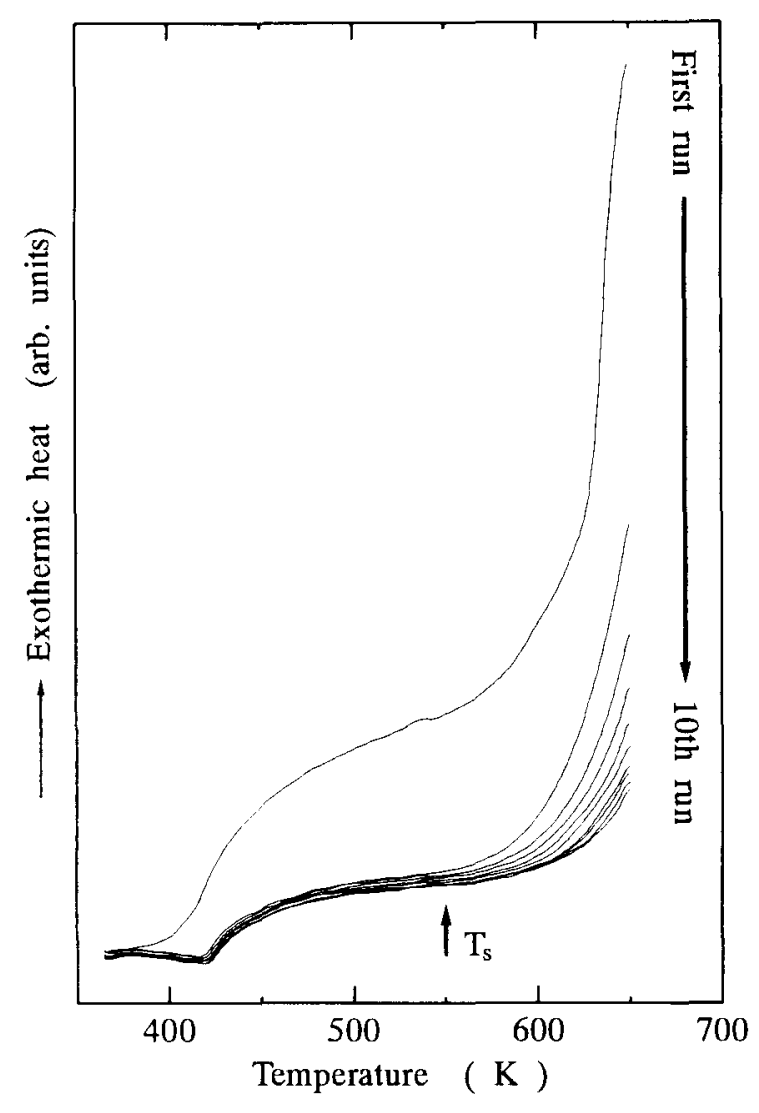

Figure 2(a) DSC curves of amorphous $\mathrm{Tb}_{22} \mathrm{Fe}_{78}$ alloy.

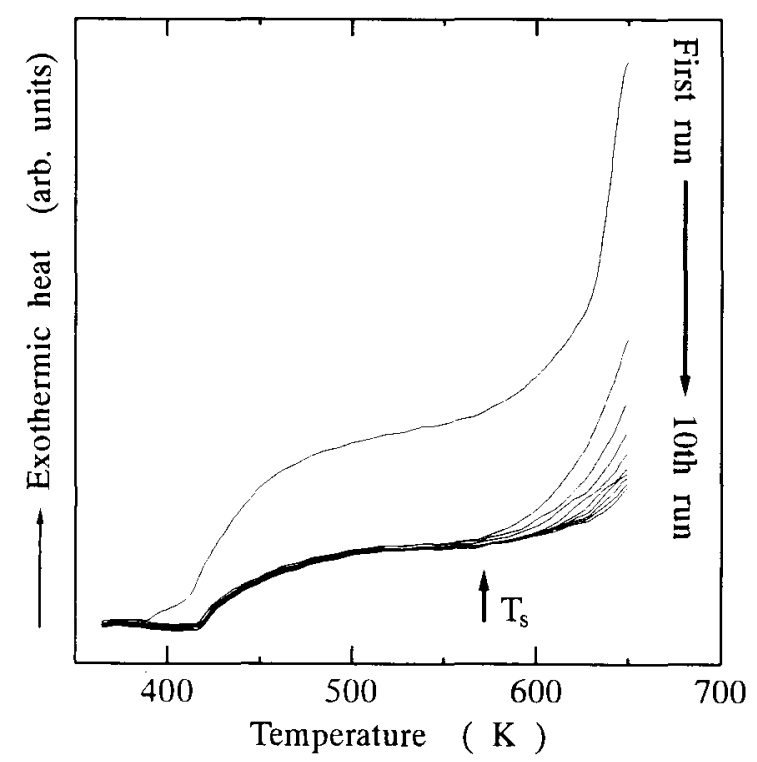

Figure 2(b) DSC curves of amorphous $\left(\mathrm{Tb}_{22} \mathrm{Fe}_{78}\right)_{98} \mathrm{Si}_{2}$ alloy.

This exothermic heat is assigned to an early stage of the transformation such as a short-range order in some structural relaxation or a relaxation of strains induced during sample preparation. The exothermic heat observed from the second heat run to the 10th heat run is attributed to a long-range order (LRO) for a structural relaxation with a long relaxation time, which needs an atomic diffusion of a long distance. In an exothermic heat range from $550 \mathrm{~K}$ to $650 \mathrm{~K}$ in Fig.2, the saturating speed $T_{\mathrm{s}}$ of $\mathrm{LRO}$ in $\left(\mathrm{Tb}_{0.22} \mathrm{Fe}_{0.78}\right)_{98} \mathrm{Si}_{2}$ is faster than that in $\mathrm{Tb}_{22} \mathrm{Fe}_{78}$. The starting temperatures of $\mathrm{LRO}$ in $\mathrm{Tb}_{22} \mathrm{Fe}_{78}$ and $\left(\mathrm{Tb}_{0.22} \mathrm{Fe}_{0.78}\right)_{98} \mathrm{Si}_{2}$ were about $550 \mathrm{~K}$ and $570 \mathrm{~K}$, respectively. Therefore, the starting temperature of LRO in $\mathrm{Tb}_{22} \mathrm{Fe}_{78}$ is lower than that in $\left(\mathrm{Tb}_{0.22} \mathrm{Fe}_{0.78}\right)_{98} \mathrm{Si}_{2}$, because the distribution of the activation energies is wider than that in $\left(\mathrm{Tb}_{0.22} \mathrm{Fe}_{0.78}\right)_{98} \mathrm{Si}_{2}$.

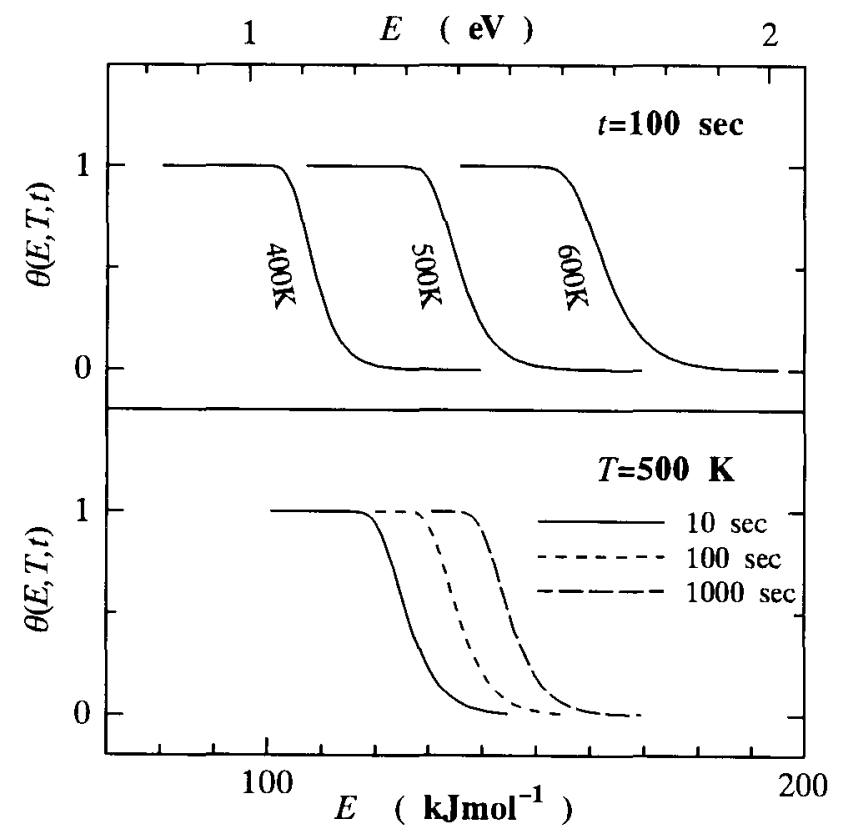

Figure 3 Dependence of the characteristic annealing function $\theta(E, T, t)$ on the time $t$ and the temperature $T$.

Gibbs et al. [1] proposed a theoretical model for the relaxation process in amorphous materials on the basis of a spectrum of available processes with a distribution of activation energy. In their model, the total change in the measured property, $\Delta P$, is given by

$$
\Delta P=\int_{0}^{E} P(E) \mathrm{d} E
$$

In the range of activation energy $E$ to $E+\mathrm{d} E$ during the structural relaxation process, the total available property $p_{0}(E)$ changes such as

$$
p(E) \mathrm{d} E=p_{0}(E)\left[1-\exp \left[-\nu_{0} t \exp \left(-\frac{E}{k T}\right)\right]\right] \mathrm{d} E
$$

where $v_{0}$ is an order of the Debye frequency $\left(v_{0} \sim 10^{12} \sec ^{-1}\right)$ Primak [2] rewrites Eq. (2) as

$$
p(E)=p_{0}(E) \theta(E, T, t),
$$

where $\theta(E, T, t)$ is defined as the characteristic annealing 
function. Thus, the function of $\theta(E, T, t)$ is a measure of the proportion of available processes at the energy $E$. Proportion as $\theta(E, T, t)$ has contributed to the relaxation property after the time $t$ at the annealing temperature $T$. The form of $\theta$ (E, $T, t)$ is given in Fig. 3, and $\theta(E, T, t)$ changes from 0.01 to 0.99 over a narrow range of $E\left(29 \mathrm{kJmol}^{-1}\right.$ at $500 \mathrm{~K}$, for example ), and the profile of $\theta(E, T, t)$ shifts along the $E$-axis linearly with a logarithmic annealing time if $T$ is fixed. Therefore the function $\theta(E, T, t)$ can be replaced by a step function with a good approximation at an energy $E_{0}$ [2] as

$$
E_{0}=k T \ln \left(v_{0} t\right)
$$

For $E<E_{0}$, the function becomes unity, for $E>E_{0}$ its value is zero. For each decade of time, the function of $E_{0}$ increases by $2.3 k T$ ( $9.6 \mathrm{kJmol}^{-1}$ at $500 \mathrm{~K}$, for example ), and thus the accuracy of the annealing time is not so necessary as that of the temperature. The step function at $E=E_{0}$ of an isothermal annealing at the temperature $T$ and the time $t$ is equivalent the approximation of $\theta(E, T, t)$. Therefore, all processes with $E<E_{0}$ contribute to the change in the property of the structural relaxation, and all processes with $E>E_{0}$ do not contribute to it. The form of $E_{0}(T, t)$ is given in Fig. 4

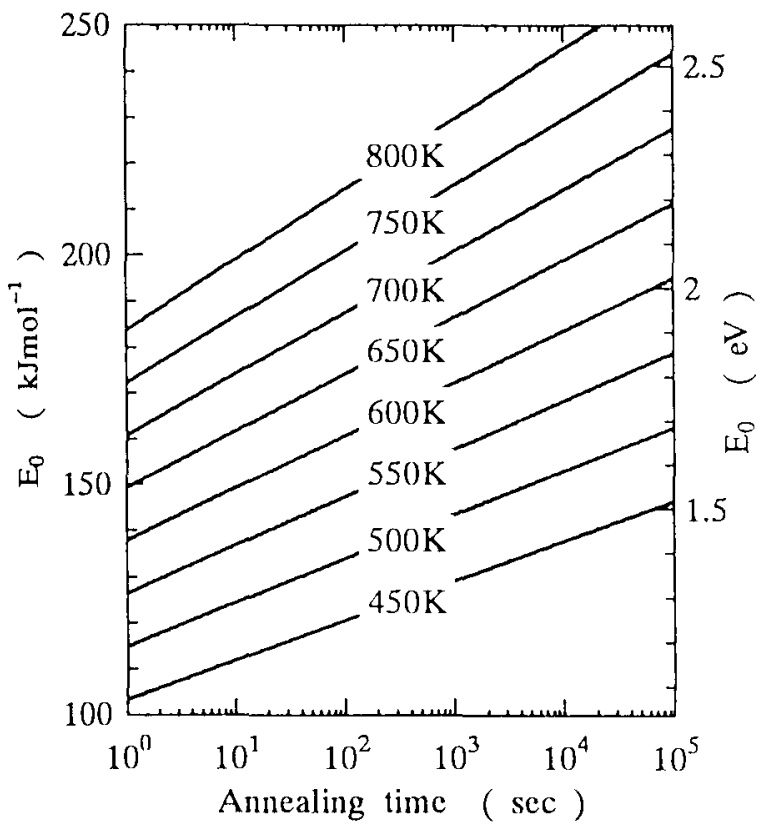

Figure 4 Dependence of the $E_{0}(T, t)$ on the time $t$ and the temperature $T$.

The activation energy for the LRO structural relaxation can be estimated from eq.(4). The lower LRO activation energies for $\mathrm{Tb}_{22} \mathrm{Fe}_{78}$ and $\left(\mathrm{Tb}_{0.22} \mathrm{Fe}_{0.78}\right)_{98} \mathrm{Si}_{2}$ are $137 \mathrm{kJmol}^{-1}$ at $550 \mathrm{~K}$ for $10 \mathrm{sec}$ and $142 \mathrm{kJmol}^{-1}$ at $570 \mathrm{~K}$ for $10 \mathrm{sec}$, respectively.

A $\lambda$-type endothermic peak is observed in Fig.2, and it is identified as the Curie temperature $T_{\mathrm{c}}$, and this temperature increases with the number of the DSC heating cycle. To observe the Curie temperature, it is necessary to keep a low temperature enough to suppress the crystallization. On the other hand, the disappearance of the $\lambda$-type peak implies the crystallization.

Figure 5 shows the annealing temperature dependence of $T_{\mathrm{c}}$, where annealing was stepped from $570 \mathrm{~K}$ to $820 \mathrm{~K}$ as the inset, and each annealing time was $10^{4} \mathrm{sec}$. The value of $T_{\mathrm{c}}$ decreases with the addition of $\mathrm{Si}$, and $T_{\mathrm{c}}$ in both the alloys increases with the annealing temperature. Finally, the $\lambda$-type peaks of the $\mathrm{Tb}_{22} \mathrm{Fe}_{78}$ and $\left(\mathrm{Tb}_{0.22} \mathrm{Fe}_{0.78}\right)_{98} \mathrm{Si}_{2}$ disappear after annealing at $770 \mathrm{~K}$ for $10^{4} \mathrm{sec}$ and $820 \mathrm{~K}$ for $10^{4} \mathrm{sec}$, respectively. The following results were obtained; $T_{\mathrm{c}}$ of the amorphous $\mathrm{Tb}$ $\mathrm{Fe}$ and $\mathrm{Tb}-\mathrm{Fe}-\mathrm{Si}$ alloys increases with the annealing temperature until crystallization. The minima of activation energies for crystallization of $\mathrm{Tb}_{22} \mathrm{Fe}_{78}$ and $\left(\mathrm{Tb}_{0.22} \mathrm{Fe}_{0.78}\right)_{98} \mathrm{Si}_{2}$ are nearly as $236 \mathrm{kJmol}^{-1}$ and $251 \mathrm{kJmol}^{-1}$, respectively. On the other hand, the activation energies for crystallization near the steep peaks in Fig. 1 estimated by the Kissinger peak shift method were $251 \mathrm{kJmol}^{-1}$ for $\mathrm{Tb}_{22} \mathrm{Fe}_{78}$ and $482 \mathrm{kJmol}^{-1}$ for $\left(\mathrm{Tb}_{0.22} \mathrm{Fe}_{0.78}\right)_{98} \mathrm{Si}_{2}$ [3]. These facts imply that the activation energy for the crystallization processes has a very wide range.

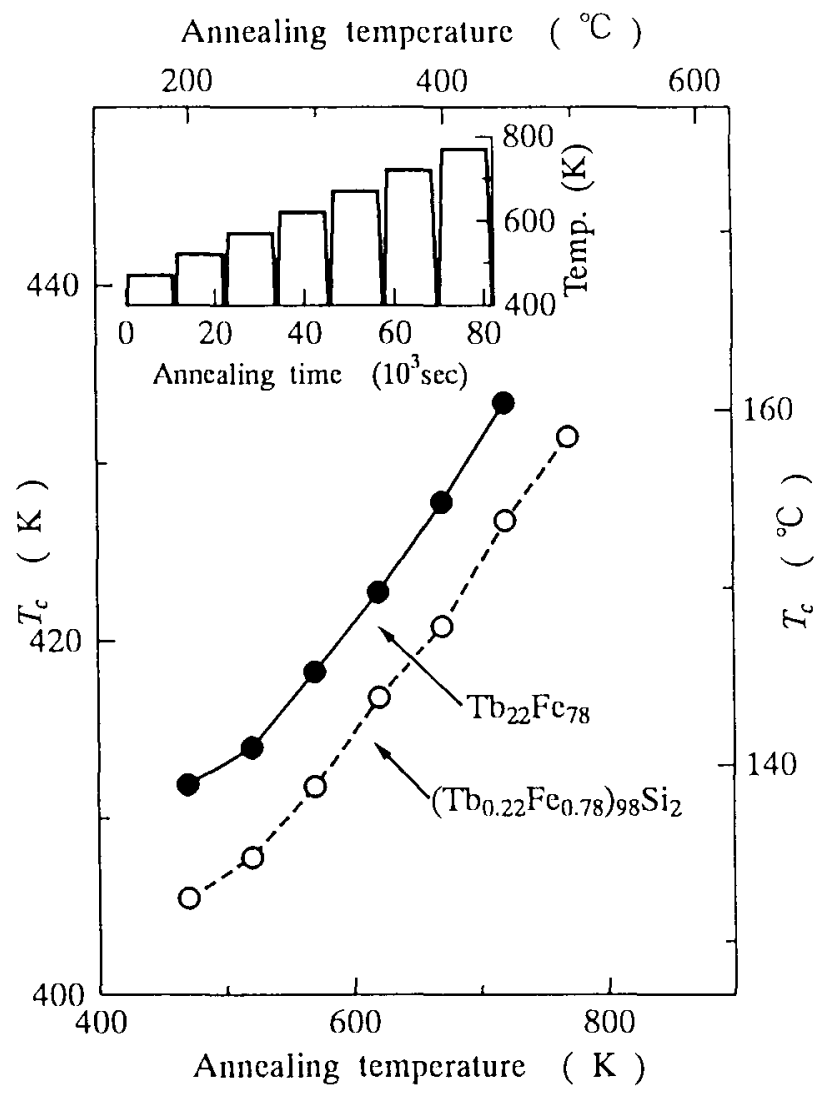

Figure 5 Dependence of $T_{\mathrm{c}}$ on the annealing temperature for amorphous $\mathrm{Tb}_{22} \mathrm{Fe}_{78}$ and $\left(\mathrm{Tb}_{0.22} \mathrm{Fe}_{0.78}\right)_{98} \mathrm{Si}_{2}$ alloys. The annealing temperature and the time are shown in the inserted figure.

Furthermore, Fig. 6 shows the annealing time dependence of $T_{\mathrm{c}}$, where the abscissa is the number of heating times. The number of heating times can be matched with the isothermal annealing time. In Fig.6, $T_{c}$ increases with the scan times. 
The $T_{\mathrm{c}}$ of $\mathrm{Tb}_{22} \mathrm{Fe}_{78}$ increases rapidly from the first to the 5 th scan and increases slightly after the 6 th scan. On the other hand, $T_{\mathrm{c}}$ of $\left(\mathrm{Tb}_{0.22} \mathrm{Fe}_{0.78}\right){ }_{98} \mathrm{Si}_{2}$ increases steadily. After annealing at $650 \mathrm{~K}$ for $10^{4} \mathrm{sec}$, the saturated value of $T_{\mathrm{c}}$ is $427.15 \mathrm{~K} \pm 0.61$ for $\mathrm{Tb}_{22} \mathrm{Fe}_{78}$ and $419.42 \mathrm{~K} \pm 0.54$ for $\left(\mathrm{Tb}_{0.22} \mathrm{Fe}_{0.78}\right)_{98} \mathrm{Si}_{2}$. From the tail values, the numbers of scan are estimated to be 74 for $\mathrm{Tb}_{22} \mathrm{Fe}_{78}$ and 47 for $\left(\mathrm{Tb}_{0.22} \mathrm{Fe}_{0.78}\right)_{98} \mathrm{Si}_{2}$. For these DSC measurements, one cyclic heating approximately corresponds to an isothermal annealing at $650 \mathrm{~K}$ for $100 \mathrm{sec}$. The maximum activation energies for LRO relaxation in $\mathrm{Tb}_{22} \mathrm{Fe}_{78}$ and ( $\left.\mathrm{Tb}_{0.22} \mathrm{Fe}_{0.8}\right)_{98} \mathrm{Si}_{2}$ are obtained to be $197 \mathrm{kJmol}^{-1}$ and $194 \mathrm{kJmol}^{-1}$, respectively. These maximum activation energies are almost nearly equal to the activation energy of Co tracer diffusion. that is, $199 \mathrm{kJmol}^{-1}$ in the $\mathrm{Tb}_{22} \mathrm{Fe}_{78}$ amorphous alloy in a structural relaxation state [4-5]. The activation energy for Co diffusion is the same as that for Fe because of the nearly same atomic radii of $\mathrm{Co}$ and $\mathrm{Fe}$. Therefore, the LRO processes are mainly caused by the Fe atom diffusion in Tb-Fe amorphous allovs.

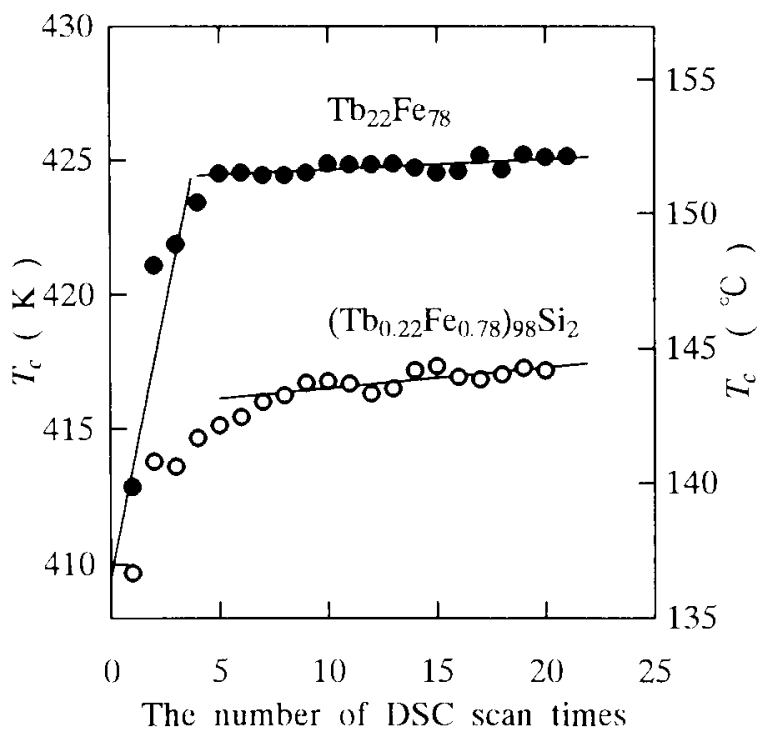

Figure 6 Dependence of $T_{0}$ on the number of DSC scan for amorphous $\mathrm{Tb}_{22} \mathrm{Fe}_{78}$ and $\left(\mathrm{Tb}_{0.22} \mathrm{Fe}_{0.78}\right)_{08} \mathrm{Si}_{2}$ alloys.

Reversibility of structural relaxation [6-7] is shown in Fig.7, where a cyclic DSC measurement of $\mathrm{Tb}_{22} \mathrm{Fe}_{78}$ and $\left(\mathrm{Tb}_{0.22} \mathrm{Fe}_{0.78}\right)_{08} \mathrm{Si}_{2}$ after annealing at $650 \mathrm{~K}$ for $10^{4} \mathrm{sec}$ was made for 13 times in the temperature range from $330 \mathrm{~K}$ to $650 \mathrm{~K}$ at the scan speed of $0.2 \mathrm{Ksec}^{-1}$. The exothermic heat of $\mathrm{Tb}_{22} \mathrm{Fe}_{78}$ is saturated more rapidly than that of $\left(\mathrm{Tb}_{0.22} \mathrm{Fe}_{0.78}\right)_{98} \mathrm{Si}_{2}$. This implies that the addition of Si retards the rate of reversibility of the structural relaxation. Furthermore, it is said that the addition of $\mathrm{Si}$ also depresses the rate of saturation of $T_{\mathrm{c}}$ as shown in Fig.6.
In summary, the activation energy for LRO relaxation is obtained to be $137-197 \mathrm{kJmol}^{-1}$ for $\mathrm{Tb}_{22} \mathrm{Fe}_{78}$ and $142-194 \mathrm{kJmol}^{-1}$ for $\left(\mathrm{Tb}_{0.22} \mathrm{Fe}_{0.78}\right)_{98} \mathrm{Si}_{2}$. The distribution of activation energies of $\mathrm{Tb}_{22} \mathrm{Fe}_{78}$ is wider than that of $\left(\mathrm{Tb}_{0.22} \mathrm{Fe}_{0.78}\right){ }_{08} \mathrm{Si}_{2}$. Therefore, the addition of $\mathrm{Si}$ retards the diffusivity of $\mathrm{Fe}$ and $\mathrm{Co}$, and decreases the rate of both the structural relaxation and the reversible relaxation, because of the covalent bonding in the metal-metalloid type ( $\left.\mathrm{Tb}_{0.22} \mathrm{Fe}_{0.78}\right)_{08} \mathrm{Si}_{2}$ amorphous alloy. Consequently, the addition of $\mathrm{Si}$ is proved to improve the thermal stability at low temperatures, corresponding to the pulse-heated recording temperatures of magneto-optical recording amorphous media.

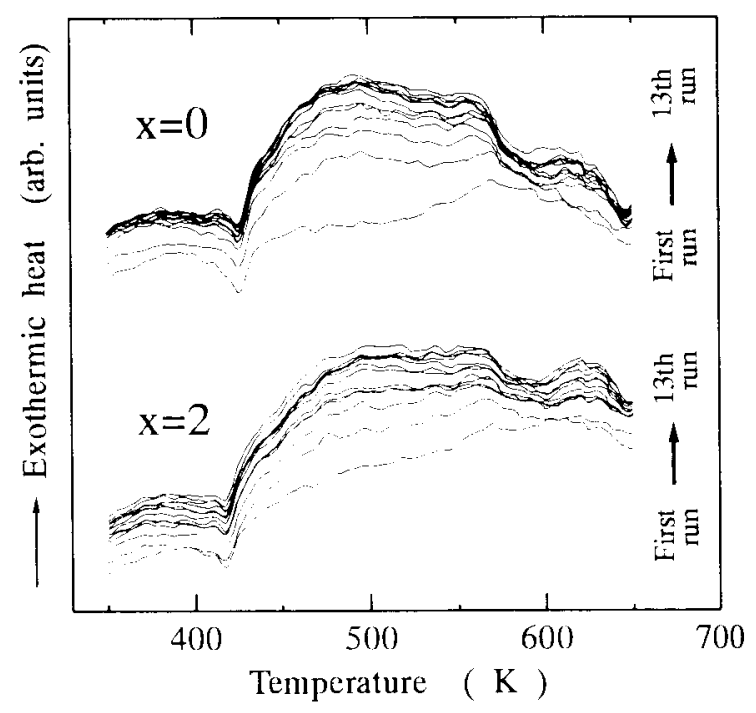

Figure 7 DSC curves of amorphous ( $\left.\mathrm{Tb}_{0222} \mathrm{Fe}_{0.78}\right)_{100-\mathrm{x}} \mathrm{Si} \mathrm{i}_{\mathrm{x}}$ alloys. The specimens were cyclic-heated after annealing at $650 \mathrm{~K}$ for $10^{4} \mathrm{sec}$.

\section{REFERENCES}

[1] M. R. J. Gibbs. J. E. Evetts and J. A. Leake, J. Mater. Sci. 18, 278 (1983).

[2] W. Primak. Phys. Rev. 100, 1677 (1955).

[3] K. Yamada. M. Oumi. Y. Iijima and K. Fukamichi, Abstracts of The 120th Spring Meeting of the Japan Institute of Metals, Tokyo, Japan, 88 (1997).

[4] K. Yamada, Y. Iijima and K. Fukamichi, Defect and Diffusion Forum, 143-147. 765 (1997).

[5] K. Yamada, Y. Iijima and K. Fukamichi. J. Mater. Res. 8, 2231 (1993).

[6] A. Inoue. T. Masumoto and H. S. Chen, J. Mater. Sci. 19, 3953 (1984).

[7] Y. Takahara. A. Morita. T. Takeda and H. Matuda. J. Japan Inst. Metals, 54, 752 (1990). 